Research Article

\title{
Armed Conflict and Child Weight in DR Congo
}

\author{
Kien Le $\mathbb{D}$ \\ Faculty of Economics and Public Management, Ho Chi Minh City Open University, Ho Chi Minh City, Vietnam
}

Correspondence should be addressed to Kien Le; kien.le.int@gmail.com

Received 3 July 2021; Revised 23 August 2021; Accepted 26 August 2021; Published 3 September 2021

Academic Editor: Carol J. Burns

Copyright (c) 2021 Kien Le. This is an open access article distributed under the Creative Commons Attribution License, which permits unrestricted use, distribution, and reproduction in any medium, provided the original work is properly cited.

\begin{abstract}
This paper investigates the extent to which armed conflict influences the weight of young children in the Democratic Republic of the Congo. Exploiting the variation across districts in exposure to armed conflict and the within-district variation in the timing of whether the child was exposed to armed conflict due to birth timing within a difference-in-differences framework, we detect adverse impacts of conflict exposure to child weight. Specifically, experiencing armed conflict makes children weigh less for their age and weigh less for their height by 0.20 and 0.24 standard deviations, respectively. Armed conflict also increases the probability of children being underweight and wasted by 4.7 and 2.7 percentage points, respectively. Our heterogeneity analyses reveal that children of disadvantaged backgrounds, i.e., those born to low-educated mothers, poor mothers, and rural mothers, tend to be disproportionately affected. Our study calls for effective measures to mitigate the detrimental repercussions of armed conflict.
\end{abstract}

\section{Introduction}

Armed conflict is a threat to global peace and an obstacle to our progress toward sustainable development. At the aggregate level, conflict discourages capital accumulation and destroys production capacities, thus depressing economic growth $[1,2]$. The estimated financial cost of armed conflict between 1960 and 2014 is approximately US $\$ 26.8$ trillion (in 2010 constant prices), equivalent to $33 \%$ of the 2014 global GDP [3]. At the microlevel, armed conflict imposes severe disruptions to individuals' life. Not only does conflict bring deaths and permanent injuries but it also entails serious hidden casualties, leading people to die for years after the end of the conflict [2]. The atrocious cost of conflict also lies in decreasing the quality of life in almost all aspects such as increasing illnesses, reducing incomes, and worsening educational outcomes $[4,5]$.

This study investigates the extent to which armed conflict influences the weight of young children in the Democratic Republic of the Congo (DR Congo). We are particularly interested in this second-largest country in Africa because it has been plagued by armed conflict and political violence for decades. Since the early 1990s, the country has been home to some of the world's deadliest wars since World War II, taking away millions of lives. During our study period of 2000-2015, the country experienced approximately 70 armed conflicts each year (Table 1). The contribution of the study is three folds. First, we focus on the less salient yet critical cost of armed conflict, the cost to early human health (weight in early childhood), while other studies tend to concentrate on individuals with urgent humanitarian needs [6]. Second, our study context is DR Congo, one of the most conflict-afflicted and one of the poorest countries in the world. It is expected that DR Congolese children are especially vulnerable to the dread of conflict. Quantifying the impacts of conflict exposure on the health of DR Congolese children will shed additional light on our understanding of the conflict-human health relationship, which can help policymakers implement necessary interventions in a timely manner. Finally, we conduct a rigorous heterogeneity analysis to identify the most susceptible groups which may need extra attention from policymakers.

To evaluate the impacts of armed conflict exposure on a child's weight, we employ the difference-in-differences model. The identification comes from variation across districts in exposure to armed conflict and the within-district variation in the timing of whether the child was exposed to armed conflict due to birth timing. Under this empirical setup, we compare the weight measures of children in 
TABLE 1: Temporal distribution of armed conflict.

\begin{tabular}{ccccc}
\hline Year & $\begin{array}{c}\text { State-based } \\
\text { conflicts }\end{array}$ & $\begin{array}{c}\text { Nonstate } \\
\text { conflicts }\end{array}$ & $\begin{array}{c}\text { One-sided } \\
\text { conflicts }\end{array}$ & $\begin{array}{c}\text { Total number } \\
\text { of conflicts }\end{array}$ \\
\hline 2000 & 28 & 17 & 15 & 60 \\
2001 & 8 & 5 & 11 & 24 \\
2002 & 3 & 28 & 23 & 54 \\
2003 & 0 & 20 & 19 & 39 \\
2004 & 0 & 2 & 19 & 21 \\
2005 & 0 & 0 & 14 & 14 \\
2006 & 7 & 2 & 45 & 54 \\
2007 & 4 & 1 & 74 & 79 \\
2008 & 14 & 1 & 41 & 56 \\
2009 & 30 & 0 & 107 & 137 \\
2010 & 34 & 0 & 42 & 76 \\
2011 & 41 & 5 & 63 & 109 \\
2012 & 22 & 2 & 44 & 68 \\
2013 & 61 & 15 & 61 & 137 \\
2014 & 37 & 7 & 46 & 90 \\
2015 & 39 & 2 & 62 & 103 \\
\hline
\end{tabular}

Any nongovernmental formalized group using armed force against a government is classified as state-based conflict. Any nongovernmental group using armed force against another similarly formalized group is classified as nonstate conflict. Any nongovernmental group using armed force against unorganized civilians is classified as one-sided conflict.

conflict districts with those of similarly aged children in nonconflict districts. The data for our paper are retrieved from the DR Congo Demographic and Health Survey supplemented with the Global Positioning System (DHSGPS) and the Uppsala Conflict Data Program Georeferenced Event Dataset (UCDP-GED). The DR Congo DHS-GPS offers a variety of child weight measures as well as other important characteristics. The UCDP-GED provides detailed information on armed conflict.

Our study reaches the following findings. First, we present compelling evidence that exposure to armed conflict adversely affects the weight outcomes of under-five DR Congolese children. In particular, experiencing conflict makes the child weigh less for their age and weight less for their height by 0.20 and 0.24 standard deviation, respectively. Armed conflict exposure raises the likelihood of the child being underweight and wasted by 4.7 and 2.7 percentage points, respectively. These estimates correspond to the 18 and 35\% increases in the incidences of underweight and wasting, respectively, compared to the sample averages. Second, we detect heterogeneous impacts of armed conflict across different subgroups of the population. Specifically, children of disadvantaged socioeconomic backgrounds, i.e., those born to low-educated mothers, poor mothers, and rural mothers, are disproportionately affected.

Our findings highlight the hidden but dreadful cost of armed conflict. By inducing inadequate nutrition to young children, armed conflict can be devastating to human development in the short, medium, and long run. Particularly, early childhood undernutrition weakens the child's immune system, lowers school achievement, and raises behavioral abnormalities in the short and medium run $[7,8]$. In the longer run, the repercussions of early-life undernutrition persist into adulthood such as permanent growth deficit, cognitive impairment, and declining productivity $[9,10]$.
Therefore, armed conflict not only obstructs our progress toward Sustainable Development Goal 16 (SDG-16, peace, justice, and strong institutions) but also hampers SDG-3 (good health and well-being). The study calls for effective measures to mitigate the harmful consequences of armed conflict. Examples include interventions intended to ensure the nutrition and health care of children. Children from disadvantaged socioeconomic backgrounds should receive priorities as they tend to be the most vulnerable.

The paper proceeds as follows. Section 2 discusses related literature. Section 3 describes the data. Section 4 presents the empirical methodology. Section 5 discusses our findings. Section 6 concludes.

\section{Literature Review}

Our study is related to two strands of literature. The first strand of literature focuses on the cost of armed conflict. It is documented that armed conflict destroys production capacity, impedes economic growth rate, and depresses standard of living $[1,2]$. The insurmountable expenditure on the military during conflict implies substantial foreign debt, which can lead to the discouragement of new foreign investments, domestic as well as foreign capital flight [11]. Armed conflict is also associated with the depreciation of human capital. Specifically, both the quantity and quality of education are reduced by the occurrence of conflict as it disrupts learning and destroys schooling infrastructure $[4,12]$. Human health is also severely affected by conflict. It is shown that armed conflict brings deaths and permanent injuries to exposed individuals, with serious hidden casualties leading people to die for years after the end of the conflict [2]. Individuals can also be the target of violence during conflict, which substantially depreciates their health $[5,13]$.

The studies on the vulnerability of children's health to the adverse consequences of armed conflict are closest to our paper. Particularly, prior studies present compelling evidence that fetal exposure to armed conflict worsens infant health in terms of lower birth weight and shorter gestational age $[14,15]$. Not only infants but also young children are highly sensitive to conflict. It is reported that children in conflict zones, especially those less than five years old, tend to contract diseases such as respiratory tract infections, diarrhea, measles, malaria, and malnutrition $[16,17]$.

The second line of literature our study also fits into explores the sensitivity of children to extreme events. Prior studies show that adverse weather shocks have injurious impacts on the health outcomes of young children. Particularly, exposure to droughts reduces children's growth and makes them thinner for their age $[18,19]$. Likewise, extreme rainfall and temperature also raise the risk of undernutrition and diseases among young children [20]; [21-23]. Food shortage is another negative shock that could harm child health. Specifically, Woldemichael et al. [24] show that food shortage induced by food price surges substantially worsens children's nutritional statuses. Other studies point to the growth faltering effects of famine and document its devastation for child survival $[25,26]$. 


\section{Data}

3.1. Children Data. The data on weight measures and other child characteristics are drawn from the DR Congo Demographic and Health Survey (DHS). The DHS is a rich dataset on children under the age of five (0-59 months old). For child's weight, we employ the two main anthropometric measures from the data, namely, weight-for-age and weight-for-height. Both weight-for-age and weight-forheight are calculated for the under-five children for a given age and sex, based on the Centers for Disease Control and Prevention (CDC) Standard Deviation-derived Growth Reference Curves which are derived from the National Center for Health Statistics (NCHS)/CDC Reference Population. Therefore, weight-for-age and weight-forheight reflect a child's growth and nutrition in comparison with the international reference population of children. These two weight measures can be expressed by the z-score classification system (weight-for-age and weight-for-height $\mathrm{z}$-scores) where they are described as the number of standard deviations below or above the median of the international reference population. Besides, weight-for-age and weight-for-height can also be expressed by the percentile system (weight-for-age and weight-for-height percentiles) that indicate the ranking of the child's weight among the reference population. In addition to the z-score and percentile weight measures, we further construct two other weight indicators, underweight and wasting, which take the value of one if weight-for-age and weight-forheight $\mathrm{z}$-scores are less than -2 , respectively, and zero otherwise. The -2 threshold is established by the World Health Organization [27].

Besides, the DR Congo DHS also offers a wide range of child characteristics (month-year of birth, age, sex, birth order, plural birth indicator) and mother's characteristics (maternal age, maternal education). In this study, we restrict our sample to the DHS waves with the child weight measures and the Global Positioning System (GPS) components present, leaving us with the waves 5 (surveyed in 2007) and 6 (surveyed in 2013 and 2014) of the DR Congo DHS-GPS. These two waves together cover children born from 2002 to 2014. In the DHS-GPS, the child's household is georeferenced so that the residential cluster of the child's household can be identified with a pair of latitude and longitude, thus allowing us to identify households' residential districts. Given the spatial and temporal details from the DHS-GPS, we are able to determine whether the child was exposed to armed conflict or not (as discussed in the next section).

3.2. Conflict Data. Data on armed conflicts in DR Congo are retrieved from the Uppsala Conflict Data Program Georeferenced Event Dataset (UCDP-GED), version 19.1. The UCDP-GED records armed conflict worldwide, which also includes DR Congo. For each event of a conflict, the date and place of occurrence are recorded. As the occurrence place of each conflict event is associated with a pair of latitude and longitude, we can identify the district where the conflict happened. Therefore, we are able to merge the UCDP-GED with the DHS-GPS. Table 1 shows the temporal distribution of various types of armed conflict in DR Congo for the study period.

After merging the conflict information from the UCDP-GED with the child information from the DR Congo DHS-GPS, we can identify whether any armed conflict occurred in the child's residential district. Given the child's district, month-year of birth, the conflict occurrence date, and the survey year, we can determine whether a DR Congolese child was exposed to armed conflict. The child was considered exposed to armed conflict if the conflict occurred in the child's district after he/she was born and before the survey date. For example, for a conflict that started in April 2003 and ended in November 2005 in a given district, we consider children entering the survey in 2007 (DR Congo DHS-GPS, wave 5). Children born before November 2005 were exposed to the conflict whereas children born in December 2005 and afterward were unexposed. However, if the conflict lasted until 2008, then all children in the 2007 survey were exposed to armed conflict. Our main explanatory variable, Exposed, is an indicator taking the value of one if the child's district experienced conflict after the child was born and before the survey date (i.e., the child was exposed to armed conflict), zero otherwise (i.e., the child was unexposed to conflict).

3.3. Estimation Sample. Our estimation sample consists of approximately 10,600 DR Congolese children. The descriptive statistics of dependent and independent variables are presented in Panels A and B of Table 2, respectively. According to Panel A, the weight-for-age and weight-for-height $\mathrm{z}$-scores take the mean value of -1.20 and -0.37 standard deviations. The negative values indicate that DR Congolese children have worse nutrition statuses compared to the international reference population that also includes children from higher-income countries. Unsurprisingly, the rankings of weight-for-age and weight-for-height of DR Congolese children are 22.42 and 38.96 percentiles, on average, all falling below 50. Roughly $27.6 \%$ and $7.7 \%$ of our sampled children are underweight and wasted, respectively. Summary statistics of independent variables are displayed in Panel B. Approximately $22 \%$ of children were exposed to armed conflict. Mothers complete 5.04 years of education, on average. The mean values of the mother's current age and age at birth are 29.26 and 27.34, respectively. Approximately $67.4 \%$ of the mothers live in rural areas. Children are 28.24 months old, on average. Around $49.5 \%$ of children are male. The mean birth order is 3.95. The fraction of plural birth is $1.6 \%$. In addition to the afterbirth exposure, we also construct an indicator for prenatal exposure to conflict (Before Birth Exposure). The fraction of children experiencing conflict during the in utero period is $10.2 \%$. 
TABLe 2: Summary statistics.

\begin{tabular}{lccc}
\hline & $\begin{array}{c}\text { Mean } \\
(1)\end{array}$ & $\begin{array}{c}\text { SD } \\
(2)\end{array}$ & $\begin{array}{c}\text { Observations } \\
(3)\end{array}$ \\
\hline Panel A: dependent variables & & & \\
Weight-for-age Z-Score & -1.196 & 1.327 & 10,684 \\
Weight-for-age percentile & 22.42 & 27.34 & 10,540 \\
Underweight & 0.276 & 0.447 & 10,684 \\
Weight-for-height Z-Score & -0.367 & 1.275 & 10,684 \\
Weight-for-height percentile & 38.96 & 29.52 & 10,540 \\
Wasting & 0.077 & 0.267 & 10,684 \\
\hline Panel B: independent variables & & & \\
Exposure & 0.221 & 0.415 & 10,684 \\
Mother's education & 5.041 & 5.126 & 10,684 \\
Mother's current age & 29.25 & 6.963 & 10,684 \\
Mother's age at birth & 27.34 & 6.812 & 10,684 \\
Mother residing in rural & 0.674 & 0.468 & 10,684 \\
Child's age in month & 28.23 & 17.18 & 10,684 \\
Male child & 0.495 & 0.500 & 10,684 \\
Child's birth order & 3.953 & 2.507 & 10,684 \\
Plural birth & 0.016 & 0.126 & 10,684 \\
Before birth exposure & 0.102 & 0.303 & 10,684 \\
\hline
\end{tabular}

\section{Empirical Methodology}

To evaluate the effects of exposure to armed conflict on the weight measures in early childhood of DR Congolese children, we implement the following regression model:

$$
Y_{\text {irbt }}=\beta_{0}+\beta_{1} \text { Exposure }_{\mathrm{rbt}}+\lambda_{r}+\gamma_{b}+\delta_{t}+X_{\text {irbt }}^{\prime} \Omega+\varepsilon_{\text {irbt }},
$$

where the subscripts $i, r, b$, and $t$ stand for the child, residential district, birth month-year, and survey year, respectively. The variable $Y_{\mathrm{irbt}}$ is our outcome of interest, including the six child weight measures as presented in Section 3.1 (weight-for-age $\mathrm{z}$-score, weight-for-age percentile, underweight, weight-for-height $\mathrm{z}$-score, weight-for-height percentile, and wasting). Our main explanatory variable is Exposure $_{\mathrm{rbt}}$, an indicator that takes the value of one if the child's district experienced conflict after the child was born and before the survey date, zero otherwise (details are discussed in Section 3.2).

We further include in our regression equation a set of variables $\left\{\lambda_{r}, \gamma_{b}, \delta_{t}\right\}$ as a residential district, birth monthyear, and survey year fixed effects, respectively. Besides, we add the vector $X_{\text {irbt }}^{\prime}$ to capture mother and child characteristics, such as (i) mother's years of education, mother's age at birth (and its squared term), mother's current age (and its squared term), and (ii) child's gender, child's birth order, child's age in months (and its squared term), whether the child is a singleton birth, and an indicator for conflict exposure during the intrauterine period. Finally, $\varepsilon_{\text {irbt }}$ stands for the error term. We cluster the standard errors throughout the paper at the residential district level.

The coefficient of interest is $\beta_{1}$ which captures how exposure to armed conflict affects child weight. Our empirical setup is the difference-in-differences model where the identification comes from the differential timing and location of the conflict. Specifically, we rely on the variation across districts in exposure to armed conflict and the withindistrict variation in the timing of whether the child was exposed to armed conflict due to birth timing. Therefore, under this empirical setup, the weight measures of children in conflict districts are compared with those of similarly aged children in nonconflict districts. The empirical model rests on the assumption that the average weight differences across cohorts (born before or after the conflict ended) would be similar between conflict and nonconflict districts if armed conflict did not occur.

\section{Results}

5.1. Main Results. The estimated impacts of armed conflict on weight-for-age and weight-for-height are displayed in Tables 3 and 4, respectively. Each column is a separate regression and the column heading indicates the independent variable. All regressions control for mother characteristics (mother's educational year, mother's current age, and its squared term, mother's age at birth, and its squared term), child characteristics (child's age in months, and its squared term, child's gender, child's birth order, whether the child is plural birth, and an indicator for in utero exposure to conflict), residential district, birth month-year, and survey wave fixed effects.

The results in Table 3 point to the negative impacts of armed conflict on child's weight-for-age. According to Column 1, experiencing conflict is associated with a 0.20 standard deviation decrease in weight-for-age z-score. Using the percentile system leaves the conclusion unchanged as exposure to conflict reduces a child's weight-for-age ranking by 4.27 percentiles (Column 2). Evident from Column 3, DR Congolese children exposed to armed conflict are 4.7 percentage points more likely to be underweight. Taking the fraction of underweight children in Table 2 as the benchmark, the estimate represents a $17.6 \%$ increase in the incidence of underweight.

Moving to the results on weight-for-height in Table 4, we also detect an adverse relationship between armed conflict and a child's weight-for-height. Specifically, exposure to armed conflict makes children thinner for their height by 0.24 standard deviation (Column 1). The ranking of a child's weight-for-height also declines by 6.23 percentiles if he/she experienced armed conflict (Column 2). Armed conflict also raises the likelihood of the child being wasted by 2.7 percentage points. Taking the proportions of wasted children in Table 2 as the benchmark, the estimate represents the 35\% increase in the incidence of wasting.

5.2. Heterogeneity. So far we have uncovered detrimental impacts of armed conflict on child's weight measures. In this section, we proceed to explore the heterogeneity in the impacts of armed conflict for various subgroups of the population. Specifically, our heterogeneity analysis is conducted along the dimensions of maternal education, maternal wealth, maternal location, and child gender. ${ }^{3}$ (In addition to heterogeneity analysis, we also conduct a series of robustness checks and report the estimating results in 
TABLE 3: Exposure to armed conflict on child weight-for-age: main results.

\begin{tabular}{|c|c|c|c|}
\hline & $\begin{array}{c}\text { Weight-for-age } \\
\text { Z-score } \\
(1)\end{array}$ & $\begin{array}{l}\text { Weight-for-age } \\
\text { Percentile } \\
(2)\end{array}$ & $\begin{array}{c}\text { Underweight } \\
\text { (3) }\end{array}$ \\
\hline Exposure & $\begin{array}{c}-0.197^{* * *} \\
(0.057)\end{array}$ & $\begin{array}{c}-4.273^{* * *} \\
(1.346)\end{array}$ & $\begin{array}{c}0.047^{* * * *} \\
(0.013)\end{array}$ \\
\hline Observations & 10,684 & 10,540 & 10,684 \\
\hline Mother characteristics & $\mathrm{X}$ & $\mathrm{X}$ & $\mathrm{X}$ \\
\hline Child characteristics & $\mathrm{X}$ & $\mathrm{X}$ & $\mathrm{X}$ \\
\hline All fixed effects & $\mathrm{X}$ & $\mathrm{X}$ & $\mathrm{X}$ \\
\hline
\end{tabular}

${ }^{*} p<0.1,{ }^{* *} p<0.05,{ }^{* * *} p<0.01$. Each column represents the coefficients in a separate regression. The column headings indicate dependent variables. Mother characteristics include mother's years of education, mother's current age (and its squared term), and mother's age at birth (and its squared term). Child characteristics include child's age in months (and its squared term), child's gender, child's birth order, whether the child is plural birth, and an indicator for in utero exposure to conflict. All fixed effects include residential district, birth month-year, and survey wave fixed effects. Robust standard errors are clustered at the residential district level.

TABle 4: Exposure to armed conflict on child weight-for-height: main results.

\begin{tabular}{|c|c|c|c|}
\hline & $\begin{array}{l}\text { Weight-for-height } \\
\text { Z-score } \\
(1)\end{array}$ & $\begin{array}{l}\text { Weight-for-height } \\
\text { Percentile } \\
\text { (2) }\end{array}$ & $\begin{array}{c}\text { Wasting } \\
\text { (3) }\end{array}$ \\
\hline Exposure & $\begin{array}{c}-0.242^{* * *} \\
(0.051)\end{array}$ & $\begin{array}{c}-6.234^{* * *} \\
(1.394)\end{array}$ & $\begin{array}{c}0.027^{* * *} \\
(0.010)\end{array}$ \\
\hline Observations & 10,684 & 10,540 & 10,684 \\
\hline Mother characteristics & $\mathrm{X}$ & $\mathrm{X}$ & $\mathrm{X}$ \\
\hline Child characteristics & $\mathrm{X}$ & $\mathrm{X}$ & $\mathrm{X}$ \\
\hline All fixed effects & $\mathrm{X}$ & $\mathrm{X}$ & $\mathrm{X}$ \\
\hline
\end{tabular}

${ }^{*} p<0.1,{ }^{* *} p<0.05$, and ${ }^{* * *} p<0.01$. Each column represents the coefficients in a separate regression. The column headings indicate dependent variables. Mother characteristics include mother's years of education, mother's current age (and its squared term), and mother's age at birth (and its squared term). Child characteristics include child's age in months (and its squared term), child's gender, child's birth order, whether the child is plural birth, and an indicator for in utero exposure to conflict. All fixed effects include residential district, birth month-year, and survey wave fixed effects. Robust standard errors are clustered at the residential district level.

Tables 5 and 6 tbl5 tbl6. In Panel A of these tables, we replace the main explanatory, which is an indicator for exposure, by the duration of exposure (in months.) In Panels $\mathrm{B}$ and $\mathrm{C}$ of the tables, we split our sample into two subgroups for children aged 0-23 months and 24-59 months. With these checks, our conclusion remains unchanged. Children exposed to conflict, regardless of age range, are more likely to have lower health outcomes.) The estimating results for weight-for-age and weight-for-height are displayed in Tables 7 and 8 , respectively. For each panel in these tables, each column is a separate regression. The column heading specifies the outcome variables. The panel name indicates the dimension of heterogeneity. Low-educated mothers are defined as mothers who did not complete primary schooling. Highly educated mothers are defined as mothers whose educational attainment is at least primary education. Poor mothers are those coming from families with the wealth index falling in the first (the bottom) quintile of the national wealth distribution. Likewise, nonpoor mothers are those coming from families with the wealth index lying in the second, third (the middle), the fourth, and the fifth (the top) quintiles of the national wealth distribution.

Examining if armed conflicts differentially affect children born to mothers of different levels of education, we find that the impacts of armed conflict mostly fall on children born to low-educated mothers. Specifically, evident from Panel A of Tables 7 and 8, exposure to armed conflict makes DR Congolese children of low-educated mothers thinner for their age and thinner for their height by 0.27 standard deviation. Their rankings on weight-for-age and weight-forheight also decline by 5.88 and 6.34 percentiles if they were exposed to armed conflict, respectively. Experiencing armed conflict further raises the incidences of underweight and wasting by 5.9 and 4.9 percentage points among children born to low-educated mothers. As shown in Panel B of Tables 7 and 8 , the impacts on children born to highly educated mothers are smaller in magnitude compared to the impacts on children born to low-educated mothers and some of the estimates even fall short of statistical significance. Particularly, exposure to armed conflict makes children of highly educated mothers more likely to be underweight by 2.7 percentage points (the estimate is statistically significant at $10 \%$ ) and there is not enough statistical evidence for the impacts on weight-for-age $\mathrm{z}$-score and weight-for-age percentile (Panel B, Table 7). Evident from Panel B of Table 8, conflict exposure decreases the weightfor-height $\mathrm{z}$-score and weight-for-height ranking of children born to highly educated mothers by 0.19 standard deviations and 5.40 percentiles, respectively (approximately 32 and 15\% smaller in magnitude compared to the corresponding estimates for children of low-educated mothers. ${ }^{4}$ (This finding 
TABLE 5: Exposure to armed conflict on child weight-for-age: other tests.

\begin{tabular}{|c|c|c|c|}
\hline & $\begin{array}{l}\text { Weight-for-age Z-score } \\
\text { (1) }\end{array}$ & $\begin{array}{l}\text { Weight-for-age percentile } \\
\text { (2) }\end{array}$ & $\begin{array}{l}\text { Underweight } \\
\text { (3) }\end{array}$ \\
\hline \multicolumn{4}{|c|}{ Panel A: conflict duration (in months) } \\
\hline Exposure duration & $\begin{array}{c}-0.020^{* * *} \\
(0.005)\end{array}$ & $\begin{array}{c}-0.401^{* * *} \\
(0.098)\end{array}$ & $\begin{array}{c}0.005^{* * *} \\
(0.002)\end{array}$ \\
\hline \multicolumn{4}{|c|}{ Panel B: children 0-23 months } \\
\hline Exposure & $\begin{array}{c}-0.243^{* * *} \\
(0.080)\end{array}$ & $\begin{array}{c}-5.969^{* * *} \\
(1.781)\end{array}$ & $\begin{array}{c}0.071^{* * *} \\
(0.024)\end{array}$ \\
\hline \multicolumn{4}{|c|}{ Panel C: children 24-59 months } \\
\hline Exposure & $\begin{array}{c}-0.258^{* * *} \\
(0.063)\end{array}$ & $\begin{array}{c}-5.084^{* * *} \\
(1.198)\end{array}$ & $\begin{array}{c}0.062^{* *} \\
(0.025)\end{array}$ \\
\hline Mother characteristics & $\mathrm{X}$ & $\mathrm{X}$ & $\mathrm{X}$ \\
\hline Child characteristics & $\mathrm{X}$ & $\mathrm{X}$ & $\mathrm{X}$ \\
\hline All fixed effects & $\mathrm{X}$ & $\mathrm{X}$ & $\mathrm{X}$ \\
\hline
\end{tabular}

${ }^{*} p<0.1,{ }^{* *} p<0.05,{ }^{* * *} p<0.01$. Each column represents the coefficients in a separate regression. The column headings indicate dependent variables. Mother characteristics include mother's years of education, mother's current (and its squared term), and mother's age at birth (and its squared term). Child characteristics include child's age in months (and its squared term), child's gender, child's birth order, and whether the child is plural birth. All fixed effects include residential cluster, birth year, birth month, and survey wave fixed effects. Robust standard errors are clustered at the residential cluster level.

TABLE 6: Exposure to armed conflict on child weight-for-height: other tests.

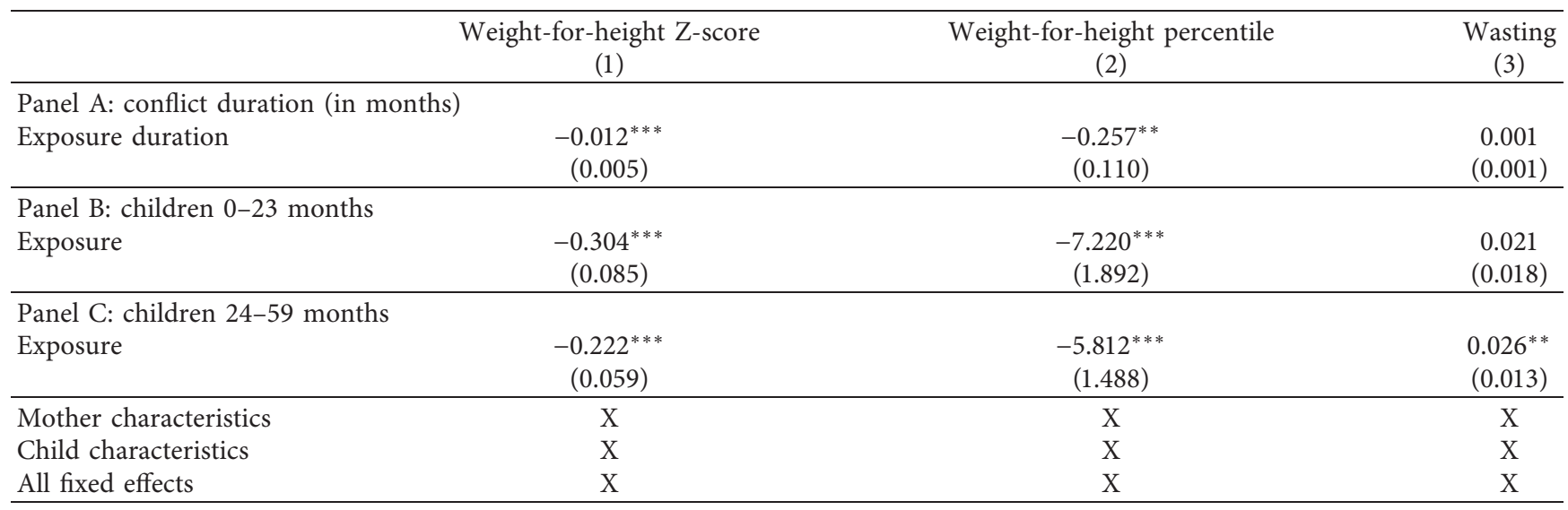

${ }^{*} p<0.1,{ }^{* *} p<0.05,{ }^{* * *} p<0.01$. Each column represents the coefficients in a separate regression. The column headings indicate dependent variables. Mother characteristics include mother's years of education, mother's current (and its squared term), and mother's age at birth (and its squared term). Child characteristics include child's age in months (and its squared term), child's gender, child's birth order, and whether the child is plural birth. All fixed effects include residential cluster, birth year, birth month, and survey wave fixed effects. Robust standard errors are clustered at the residential cluster level.

TABle 7: Exposure to armed conflict on child weight-for-age heterogeneity.

\begin{tabular}{|c|c|c|c|}
\hline & $\begin{array}{c}\text { Weight-for-age } \\
\text { Z-score } \\
(1)\end{array}$ & $\begin{array}{l}\text { Weight-for-age } \\
\text { Percentile } \\
\text { (2) }\end{array}$ & $\begin{array}{c}\text { Underweight } \\
\text { (3) }\end{array}$ \\
\hline \multicolumn{4}{|c|}{ Panel A: low education mothers } \\
\hline Exposure & $\begin{array}{c}-0.272^{* * *} \\
(0.078)\end{array}$ & $\begin{array}{c}-5.875^{* * *} \\
(1.787)\end{array}$ & $\begin{array}{c}0.059^{* * *} \\
(0.021)\end{array}$ \\
\hline \multicolumn{4}{|c|}{ Panel B: high education mothers } \\
\hline Exposure & $\begin{array}{l}-0.093 \\
(0.069) \\
\end{array}$ & $\begin{array}{l}-2.366 \\
(1.692) \\
\end{array}$ & $\begin{array}{l}0.027^{*} \\
(0.015) \\
\end{array}$ \\
\hline \multicolumn{4}{|c|}{ Panel C: poor mothers (1st wealth quintile) } \\
\hline Exposure & $\begin{array}{c}-0.284^{* *} \\
(0.140)\end{array}$ & $\begin{array}{c}-5.017^{*} \\
(2.918)\end{array}$ & $\begin{array}{c}0.089^{* *} \\
(0.045)\end{array}$ \\
\hline \multicolumn{4}{|c|}{ Panel D: nonpoor mothers (other wealth quintiles) } \\
\hline Exposure & $\begin{array}{c}-0.205^{* * *} \\
(0.063)\end{array}$ & $\begin{array}{c}-4.621^{* * *} \\
(1.436)\end{array}$ & $\begin{array}{c}0.049^{* * *} \\
(0.014)\end{array}$ \\
\hline
\end{tabular}


TABle 7: Continued.

\begin{tabular}{|c|c|c|c|}
\hline & $\begin{array}{c}\text { Weight-for-age } \\
\text { Z-score } \\
(1) \\
\end{array}$ & $\begin{array}{l}\text { Weight-for-age } \\
\text { Percentile } \\
(2) \\
\end{array}$ & $\begin{array}{c}\text { Underweight } \\
\text { (3) } \\
\end{array}$ \\
\hline \multicolumn{4}{|l|}{ Panel E: rural mothers } \\
\hline Exposure & $\begin{array}{c}-0.182^{* *} \\
(0.074) \\
\end{array}$ & $\begin{array}{c}-4.765^{* * *} \\
(1.792) \\
\end{array}$ & $\begin{array}{c}0.064^{* * *} \\
(0.021) \\
\end{array}$ \\
\hline \multicolumn{4}{|l|}{ Panel F: urban mothers } \\
\hline Exposure & $\begin{array}{r}-0.145^{*} \\
(0.083) \\
\end{array}$ & $\begin{array}{l}-2.554 \\
(1.920) \\
\end{array}$ & $\begin{array}{l}0.031^{*} \\
(0.018)\end{array}$ \\
\hline \multicolumn{4}{|l|}{ Panel G: female children } \\
\hline Exposure & $\begin{array}{c}-0.211^{* * *} \\
(0.069)\end{array}$ & $\begin{array}{c}-5.571^{* * *} \\
(1.443) \\
\end{array}$ & $\begin{array}{c}0.053^{* * *} \\
(0.020)\end{array}$ \\
\hline \multicolumn{4}{|l|}{ Panel H: male children } \\
\hline Exposure & $\begin{array}{c}-0.171^{* *} \\
(0.073) \\
\end{array}$ & $\begin{array}{c}-3.112^{*} \\
(1.691) \\
\end{array}$ & $\begin{array}{c}0.033 \\
(0.021) \\
\end{array}$ \\
\hline Mother characteristics & $\mathrm{X}$ & $\mathrm{X}$ & $\mathrm{X}$ \\
\hline Child characteristics & $\mathrm{X}$ & $\mathrm{X}$ & $\mathrm{X}$ \\
\hline All fixed effects & $\mathrm{X}$ & $\mathrm{X}$ & $\mathrm{X}$ \\
\hline
\end{tabular}

TABLE 8: Exposure to armed conflict on child weight-for-height heterogeneity.

\begin{tabular}{|c|c|c|c|}
\hline & $\begin{array}{c}\text { Weight-for-height } \\
\text { Z-score } \\
(1)\end{array}$ & $\begin{array}{c}\text { Weight-for-height } \\
\text { Percentile } \\
(2)\end{array}$ & $\begin{array}{c}\text { Wasting } \\
\text { (3) }\end{array}$ \\
\hline \multicolumn{4}{|c|}{ Panel A: low education mothers } \\
\hline Exposure & $\begin{array}{c}-0.277^{* * *} \\
(0.082)\end{array}$ & $\begin{array}{l}-6.342^{* * *} \\
(2.123)\end{array}$ & $\begin{array}{c}0.049^{* * *} \\
(0.015)\end{array}$ \\
\hline \multicolumn{4}{|c|}{ Panel B: high education mothers } \\
\hline Exposure & $\begin{array}{c}-0.190^{* * *} \\
(0.061)\end{array}$ & $\begin{array}{c}-5.396^{* * *} \\
(1.631) \\
\end{array}$ & $\begin{array}{l}-0.002 \\
(0.014)\end{array}$ \\
\hline \multicolumn{4}{|l|}{ Panel C: poor mothers } \\
\hline Exposure & $\begin{array}{c}-0.367^{* *} \\
(0.156) \\
\end{array}$ & $\begin{array}{c}-8.503^{* * *} \\
(3.196) \\
\end{array}$ & $\begin{array}{l}0.056^{* *} \\
(0.029)\end{array}$ \\
\hline \multicolumn{4}{|c|}{ Panel D: nonpoor mothers } \\
\hline Exposure & $\begin{array}{c}-0.249^{* * *} \\
(0.052)\end{array}$ & $\begin{array}{c}-6.500^{* * *} \\
(1.458) \\
\end{array}$ & $\begin{array}{c}0.025^{* *} \\
(0.010)\end{array}$ \\
\hline \multicolumn{4}{|l|}{ Panel E: rural mothers } \\
\hline Exposure & $\begin{array}{c}-0.239^{* * *} \\
(0.068)\end{array}$ & $\begin{array}{c}-5.875^{* * *} \\
(1.921) \\
\end{array}$ & $\begin{array}{c}0.016 \\
(0.015) \\
\end{array}$ \\
\hline \multicolumn{4}{|l|}{ Panel F: urban mothers } \\
\hline Exposure & $\begin{array}{c}-0.165^{* *} \\
(0.083)\end{array}$ & $\begin{array}{c}-4.568^{* *} \\
(2.262)\end{array}$ & $\begin{array}{c}0.014 \\
(0.013)\end{array}$ \\
\hline \multicolumn{4}{|l|}{ Panel G: female children } \\
\hline Exposure & $\begin{array}{c}-0.242^{* * *} \\
(0.086) \\
\end{array}$ & $\begin{array}{c}-6.883^{* * *} \\
(1.536) \\
\end{array}$ & $\begin{array}{l}0.031^{* *} \\
(0.015)\end{array}$ \\
\hline \multicolumn{4}{|l|}{ Panel H: male children } \\
\hline Exposure & $\begin{array}{c}-0.230^{* * * *} \\
(0.061)\end{array}$ & $\begin{array}{c}-5.103^{* *} \\
(2.146)\end{array}$ & $\begin{array}{c}0.018 \\
(0.012)\end{array}$ \\
\hline Mother characteristics & $\mathrm{X}$ & $\mathrm{X}$ & $\mathrm{X}$ \\
\hline Child characteristics & $\mathrm{X}$ & $\mathrm{X}$ & $\mathrm{X}$ \\
\hline All fixed effects & $\mathrm{X}$ & $\mathrm{X}$ & $\mathrm{X}$ \\
\hline
\end{tabular}


is consistent with prior studies suggesting that maternal education is an important factor influencing child health, such as the works of $[28,29]$.) The estimate for the wasting is economically and statistically indistinguishable from zero.

Exploring the heterogeneous impacts of armed conflict on child weight along the line of maternal wealth, we find that the effects are larger in magnitude for children born to poor mothers than children born to nonpoor mothers. As shown in Panel $\mathrm{C}$ of Tables 7 and 8, among children of poor mothers, experiencing armed conflict makes children weigh less for their age by 0.28 standard deviation and less for their height by 0.37 standard deviation. Their weight-for-age and weight-for-height rankings also fall by 5.02 and 8.50 percentiles, respectively. They are 8.9 and 5.6 percentage points more likely to be underweight and wasted, respectively. As shown in Panel D of Tables 7 and 8, the estimated impacts of armed conflicts on the weight measures of children born to nonpoor mothers are smaller in magnitude. Particularly, armed conflict exposure is associated with 0.21 and 0.25 standard deviation decreases in weight-for-age and weightfor-height z-scores, respectively. Children born to nonpoor mothers have their weight-for-age and weight-for-height rankings decline by 4.62 and 6.50 percentiles. They are 4.9 and 2.5 percentage points more likely to be underweight and wasted.

In addition, we find that the impacts of armed conflict tend to be more severe on children born to rural mothers. Specifically, evident from Panel E of Tables 7 and 8, exposure to armed conflict makes DR Congolese children of rural mothers thinner for their age and thinner for their height by 0.18 and 0.24 standard deviations. Their rankings on weightfor-age and weight-for-height also decline by 4.76 and 5.87 percentiles if they were exposed to armed conflict, respectively. Experiencing armed conflict further raises the incidences of underweight and wasting by 6.4 and 1.6 percentage points among children born to low-educated mothers. As shown in Panel F of Tables 7 and 8, the impacts on children born to urban mothers are smaller in magnitude compared to the impacts on children born to low-educated mothers and some of the estimates even fall short of statistical significance.

Finally, we explore the heterogeneous impacts of armed conflict on child weight along the line of child gender. We find that the effects are slightly larger in magnitude for female children. As shown in Panel G of Tables 7 and 8, among female children, experiencing armed conflict make children weigh for their age by 0.21 standard deviation less and less for their height by 0.24 standard deviation. Their weight-for-age and weight-for-height rankings also fall by 5.57 and 6.88 percentiles, respectively. They are 5.3 and 3.1 percentage points more likely to be underweight and wasted, respectively. As shown in Panel $\mathrm{H}$ of Tables 7 and 8, the estimated impacts of armed conflicts on the weight measures of male children are slightly smaller in magnitude. Particularly, armed conflict exposure is associated with 0.17 and 0.23 standard deviation decreases in weight-for-age and weight-for-height $\mathrm{z}$-scores, respectively. Male children also have their weight-for-age and weight-for-height rankings decline by 3.11 and 5.10 percentiles. They are 3.3 and 1.8 percentage points more likely to be underweight and wasted.

\section{Discussion}

Collectively, we have found that exposure to armed conflict adversely affects child weight in the context of DR Congo. Specifically, experiencing conflict is associated with the 0.20 and 0.24 standard deviation decreases in weight-for-age and weight-for-height z-scores. Child's rankings in weight-forage and weight-for-height subsequently decline by 4.27 and 6.23 percentiles, respectively, if the child was exposed to armed conflict. Conflict exposure further raises the probability of the child being underweight and wasted by 4.7 and 2.7 percentage points, respectively. Taking the fractions of underweight and wasted children in our sample as the benchmarks, these estimates correspond to the 18 and 35\% increases in the incidences of underweight and wasting. Furthermore, our heterogeneity analyses reveal that children of disadvantaged socioeconomic backgrounds, i.e., those born to low-educated mothers, poor mothers, and rural mothers, are disproportionately affected by armed conflicts.

Our findings are consistent with prior studies on the adverse impacts of armed conflict on the health outcomes of children. Experiencing armed conflict is also associated with various diseases which are lethal to young children, for example, respiratory tract infections, diarrhea, measles, malaria, and malnutrition [16, 17]. By presenting evidence on the detrimental effects of armed conflict exposure to child's weight in the context of DR Congo, our study complements prior literature on the atrocious cost of conflict to human life. Furthermore, our findings also add to the literature showing how sensitive young children are to extreme events $[19,23,26]$.

There are multiple potential mechanisms through which armed conflict can worsen child weight measures. First, different kinds of weapons used during armed conflict could impose serious injuries to children, which might adversely affect their body mass [30]. The pernicious consequences of conflict-attributable injuries might be exacerbated by limited access to adequate and timely care in combat zones [30]. Second, there is a possibility that children experiencing armed conflict might also experience other forms of violence in their community, which could aggravate their weight [31]. Third, armed conflict can adversely affect child weight through the destruction of infrastructure, especially public health infrastructure. Specifically, water supplies and wastewater systems might be disrupted, thus limiting access to clean water and posing a health threat to children. Furthermore, health care and public health systems can be destroyed during the conflict, worsening child morbidity in conflict-afflicted regions [17]. Fourth, food shortage can be another pathway to the detrimental impacts of armed conflict as agricultural production may be disrupted and international food aid may be obstructed [32]. Finally, armed conflict could lead to the displacement of many individuals, forcing children into conditions with elevated risks of communicable diseases [33], compromising their weight. 
Our study emphasizes the hidden but dreadful cost of armed conflict. Going beyond the visible consequences such as the loss of life, the destruction of production capacity, and the depression of GDP, armed conflict imposes a nonnegligible cost to human capital in the form of inadequate nutrition to young (i.e., under five years old) children. In the short and medium run, undernutrition can slow a child's growth and make common childhood infections last longer and occur more frequently [7, 34]. Furthermore, early childhood undernutrition is also associated with poor mental development, school achievement, and behavioral abnormalities [8]. The longer-run impacts of early childhood undernutrition involve permanent growth deficit and cognitive impairment $[9,10]$. To make matters worse, these injurious effects could potentially be passed on to the second generation due to the presence of intergenerational transmission. Therefore, armed conflict not only obstructs SDG-16 (peace, justice, and strong institutions) but also impedes our progress toward SDG-3 (good health and well-being). Our study calls for global efforts in the prevention and reduction of armed conflict. Effective measures should be taken to mitigate the adverse cost of conflicts, such as the provision of food and health care for children in conflict zones. Priorities should be directed to children of disadvantaged socioeconomic backgrounds such as those born to loweducated mothers and poor mothers since they tend to be the most vulnerable.

\section{Conclusion}

This paper investigates how exposure to armed conflict influences a child's weight in the context of DR Congo. To identify the impacts of interest, we employ the difference-indifferences model which exploits the variation across districts in exposure to armed conflict and the within-district variation in the timing of whether the child was exposed to armed conflict due to birth timing. The data for the study are retrieved from waves 5 and 6 of the DR Congo Demographic and Health Survey supplemented with the Global Positioning System (DHS-GPS) and the Uppsala Conflict Data Program Georeferenced Event Dataset (UCDP-GED). The DHS-GPS offers a wide range of child weight measures as well as mother and child characteristics. The latitude-longitude associated with the child's residential place allows us to merge the DHS-GPS with the conflict data from the UCDP-GED. The UCDP-GED records conflict at the event level with detailed place and date of occurrence. The information on the child's residential place, the conflict history of that place, the child's month-year of birth, and the survey year enables us to determine if the child was exposed to armed conflict.

Our study reaches the following findings. First, we detect detrimental impacts of armed conflict on the weight outcomes of under-five DR Congolese children. Specifically, conflict exposure makes children thinner for their age and thinner for their height by 0.20 and 0.24 standard deviations, respectively. Child's rankings in weight-for-age and weight-for-height subsequently decline by 4.27 and
6.23 percentiles, respectively, if the child experienced armed conflict. Armed conflict further makes children more likely to be underweight and wasted by 4.7 and 2.7 percentage points. Taking the fractions of underweight and wasted children in our sample as the benchmarks, these estimates correspond to the 18 and $35 \%$ increase in the incidences of underweight and wasting. Second, we uncover heterogeneous impacts of armed conflict across different subgroups of the population. Particularly, children of disadvantaged socioeconomic backgrounds, i.e., those born to low-educated mothers, poor mothers, and rural mothers, are disproportionately affected.

Our study underscores the less visible but salient cost of armed conflict. Particularly, armed conflict aggravates early human capital in the form of inadequate nutrition for young children. Because undernutrition weakens a child's immunity system, impairs mental and cognitive development, and raises behavioral problems, the cost of armed conflict in the short and medium run can be devastating to child development $[7,8]$. These adverse consequences could be longlasting as undernutrition in early childhood leads to lower educational attainment, declining productivity, and fewer earnings [10, 35-37]. To put it differently, armed conflict impedes our progress toward both SDG-16 (peace, justice, and strong institutions) and SDG-3 (good health and wellbeing). Our paper calls for the prevention and reduction of armed conflict, and areas with high conflict levels should be prioritized. Mitigative strategies should be implemented to minimize the adverse impacts. For instance, public assistance should be directed toward the provision of food and health care for children affected by conflict. Interventions to ensure the nutrition of children are of utmost importance and should be implemented both during and after conflicts. In addition, reconstruction initiatives targeting conflict-affected areas such as rehabilitating basic social services, rebuilding household assets and infrastructures, and assisting the return of the displaced are also critical to restoring child health. Children of disadvantaged socioeconomic backgrounds should receive extra attention as they tend to suffer the most from conflict.

\section{Data Availability}

The data underlying this study can be obtained at https:// dhsprogram.com and https://ucdp.uu.se/downloads/olddw. html.

\section{Conflicts of Interest}

The authors declare that they have no conflicts of interest.

\section{Acknowledgments}

The study was supported by The Youth Incubator for Science and Technology Program, managed by the Youth Development Science and Technology Center-Ho Chi Minh Communist Youth Union and Department of Science and Technology of Ho Chi Minh City; the contract number is “11/2020/HĐ-KHCNT-VƯ ngày 30 tháng 12 năm 2020.” 


\section{References}

[1] P. Collier and A. Hoeffler, "Conflicts," in Global Crises: Global Solutions, B. Lomborg, Ed., Cambridge University Press, Cambridge, UK, 2004.

[2] J. P. Dunne, A. Hoeffler, and A. Mack, "Armed conflicts," in Global Problems, Smart Solutions: Costs and Benefits, B. Lomborg, Ed., pp. 21-71, Cambridge University Press for Copenhagen Consensus, New York, NY, USA, 2013.

[3] A. Alamir, C. Bozzoli, T. Bruck, and O. J. De Groot, "The global economic burden of violent conflict," in Proceedings of the ECARES Working Papers, Brussels, Belgium, 2018.

[4] T. Brück, M. Di Maio, and S. H. Miaari, "Learning the hard way: the effect of violent conflict on student academic achievement," Journal of the European Economic Association, vol. 17, no. 5, pp. 1502-1537, 2019.

[5] O. Shemyakina, "The effect of armed conflict on accumulation of schooling: results from Tajikistan," Journal of Development Economics, vol. 95, no. 2, pp. 186-200, 2011.

[6] T. Bruck, P. Justino, and C. P. Martin-Shields, "Conflict and development: recent research advances and future agendas (No. 2017/178)," in Proceedings of the WIDER Working Paper, Helsinki, Finland, 2017.

[7] A. Burgess, "Undernutrition in adults and children: causes, consequences and what we can do," South Sudan Medical Journal, vol. 1, no. 2, pp. 18-22, 2008.

[8] V. J. B. Martins, T. M. M. Toledo Florêncio, L. P. Grillo et al., "Long-lasting effects of undernutrition," International Journal of Environmental Research and Public Health, vol. 8, no. 6, pp. 1817-1846, 2011.

[9] R. L. Guerrant, R. B. Oriá, S. R. Moore, M. O. Oriá, and A. A. Lima, "Malnutrition as an enteric infectious disease with long-term effects on child development," Nutrition Reviews, vol. 66 , no. 9, pp. 487-505, 2008.

[10] United Nations Children's Fund (UNICEF), World Health Organization, International Bank for Reconstruction and Development/The World Bank. Levels and Trends in Child Malnutrition: Key Findings of the 2020 Edition of the Joint Child Malnutrition Estimates, World Health Organization, Geneva, Switzerland, 2020.

[11] T. Bruck, O. J. De Groot, and C. Bozzoli, "How many bucks in a bang: on the estimation of the economic costs of conflict," in The Oxford Handbook of the Economics of Peace and ConflictOxford University Press, Oxford, UK, 2012.

[12] K. Le and M. Nguyen, "Aerial bombardment and educational attainment," International Review of Applied Economics, vol. 34, no. 3, pp. 361-383, 2020a.

[13] P. Justino, "War and poverty," in Handbook of the Economics of Peace and Conflict, M. Garfinkel and S. Skaperdas, Eds., Oxford University Press, Oxford, UK, 2012.

[14] K. Le and M. Nguyen, "Armed conflict and birth weight," Economics and Human Biology, vol. 39, Article ID 100921, 2020 b.

[15] C. Quintana-Domeque and P. Ródenas-Serrano, "The hidden costs of terrorism: the effects on health at birth," Journal of Health Economics, vol. 56, pp. 47-60, 2017.

[16] D. Guha-Sapir and O. D'Aoust, Demographic and Health Consequences of Civil Conflict, World Development Report, Washington, DC, USA, 2011.

[17] J. H. Requejo, J. Bryce, A. J. Barros et al., "Countdown to 2015 and beyond: fulfilling the health agenda for women and children," The Lancet, vol. 385, no. 9966, pp. 466-476, 2015.

[18] J. Hoddinott and B. Kinsey, "Child growth in the time of drought," Oxford Bulletin of Economics \& Statistics, vol. 63, no. 4, pp. 409-436, 2001.
[19] S. Lazzaroni and N. Wagner, "Misfortunes never come singly: structural change, multiple shocks and child malnutrition in rural Senegal," Economics and Human Biology, vol. 23, pp. 246-262, 2016.

[20] E. Skoufias and K. Vinha, "Climate variability and child height in rural Mexico," Economics and Human Biology, vol. 10, no. 1, pp. 54-73, 2012.

[21] K. Le and M. Nguyen, "In-utero exposure to rainfall variability and early childhood health," In-utero Exposure to Rainfall Variability and Early Childhood Health, World Development, vol. 144, Article ID 105485, 2021a.

[22] K. Le and M. Nguyen, The Impacts of Temperature Shocks on Birth Weight in Vietnam. Population and Development Review, Wiley, Hoboken, NJ, USA, 2021 b.

[23] M. Rabassa, E. Skoufias, and H. Jacoby, "Weather and child health in rural Nigeria," Journal of African Economies, vol. 23, no. 4, pp. 464-492, 2014.

[24] A. Woldemichael, D. Kidane, and A. Shimeles, "A tax on children? Food price inflation and health (No. 276)," in Proceedings of the African Development Bank Working Paper Series, Abidjan, Cote d'Ivoire, 2017.

[25] R. Biellik and P. Henderson, "Mortality, nutritional status, and diet during the famine in Karamoja, Uganda, 1980," The Lancet, vol. 318, no. 8259, pp. 1330-1333, 1981.

[26] G.-E. Kiros and D. P. Hogan, "War, famine and excess child mortality in Africa: the role of parental education," International Journal of Epidemiology, vol. 30, no. 3, pp. 447-455, 2001.

[27] World Health Organization, "Nutrition Landscape Information System (NLIS) country profile indicators: interpretation guide," WHO, Geneva, Switzerland, 2010, https://apps. who.int/iris/handle/10665/44397.

[28] S. Desai and S. Alva, "Maternal education and child health: is there a strong causal relationship?" Demography, vol. 35, no. 1, pp. 71-81, 1998.

[29] K. Le and M. Nguyen, "Shedding light on maternal education and child health in developing countries," World Development, vol. 133, Article ID 105005, 2020c.

[30] M. Borgman, R. I. Matos, L. H. Blackbourne, and P. C. Spinella, "Ten years of military pediatric care in Afghanistan and Iraq," Journal of Trauma and Acute Care Surgery, vol. 73, no. 6, pp. S509-S513, 2012.

[31] S. Rees, D. Silove, T. Verdial et al., "Intermittent explosive disorder amongst women in conflict affected Timor-Leste: associations with human rights trauma, ongoing violence, poverty, and injustice," PLoS One, vol. 8, no. 8, Article ID e69207, 2013.

[32] N. Nunn and N. Qian, "US food aid and civil conflict," The American Economic Review, vol. 104, no. 6, pp. 1630-1666, 2014.

[33] M. A. Connolly, M. Gayer, M. J. Ryan, P. Salama, P. Spiegel, and D. L. Heymann, "Communicable diseases in complex emergencies: impact and challenges," The Lancet, vol. 364, no. 9449, pp. 1974-1983, 2004.

[34] R. E. Black, L. H. Allen, Z. A. Bhutta et al., "Maternal and child undernutrition: global and regional exposures and health consequences," The Lancet, vol. 371, no. 9608, pp. 243-260, 2008.

[35] A. Briend and J. A. Berkley, "Long term health status of children recovering from severe acute malnutrition," The Lancet Global Health, vol. 4, no. 9, pp. e590-e591, 2016.

[36] A. Case, A. Fertig, and C. Paxson, "The lasting impact of childhood health and circumstance," Journal of Health Economics, vol. 24, no. 2, pp. 365-389, 2005. 
[37] P. Glewwe and E. A. Miguel, "The impact of child health and nutrition on education in less developed countries," in Handbook of Development Economics, T. P. Schultz and J. A. Strauss, Eds., pp. 3561-3606, North Holland Press, Amsterdam, Netherlands, 2008. 